\title{
MAKING STRATEGIC DECISIONS ON B2B E-COMMERCE MODELS: AN EMPIRICAL STUDY ON AUSTRALIAN AGRIBUSINESSES
}

\author{
Eric $\mathrm{Ng}$ \\ University of Southern Queensland \\ Toowoomba, Queensland 4350, Australia \\ eric.ng@usq.edu.au
}

\begin{abstract}
While the adoption rate of electronic commerce by organizations has grown significantly over the years and that they have achieved substantial savings and benefits, it has also presented numerous new challenges for them to conduct business activities in the electronic environment. This trend has prompted a need for existing business models to be reviewed, including the adoption of appropriate e-commerce models which is important for organizations to maximize their success in the electronic environment. This research investigates the factors influencing the selection of electronic commerce models in a business-to-business electronic environment by using depth interviews and case studies conducted with agribusinesses in Australia. The findings revealed 14 factors as being important to the selection of electronic commerce models, and this type of strategic decision is usually influenced by a combination of these factors and not just by a single dominant factor.
\end{abstract}

Keywords: E-commerce, B2B, Strategic Decision-Making, Australia, Agribusiness

\section{INTRODUCTION}

Over the years while many organizations have reengineered, downsized and cut costs in different ways, others are still investigating new strategic initiatives to deliver positive business outcomes. These strategic initiatives include the use of modern technologies to harness the benefits of electronic commerce (e-commerce) which has in turn transformed organizations by strengthening customer and supplier relationships, and establishing new markets and opportunities ${ }^{1,2}$. The emergence of 
e-commerce requires existing business models to be rethought radically to reflect the transformation required by organizations to take advantage of the many benefits offered by this new challenging environment ${ }^{3,4}$. The adoption of e-commerce has been stimulated by benefits that may include the ability to address specific, niche-market customer groups using highly customized campaigns, collaboration, quick decision-making and increased flexibility ${ }^{5,6}$. This is particularly evident in the business-to-business (B2B) segment where e-commerce has grown significantly over the years and that organizations have achieved substantial savings by conducting their business activities over the electronic environment ${ }^{\text {. }}$.

In view of the growing adoption rate of e-commerce by organizations, there is a need for them to critically review their existing business models so that they are capable of meeting the challenges presented in the e-commerce environment. The adoption of appropriate e-commerce models is therefore important for organizations that wish to maximize their success in the electronic environment. Organizations are also faced with a wide range of e-commerce models, with many factors influencing their ultimate selection of the models. The selection of B2B e-commerce models is one of many strategic decisions that organizations make in the pursuit of conducting business activities in the electronic environment. It is important to understand how organizations make these decisions and the factors that impact the process when selecting B2B e-commerce models. While previous studies have been conducted to investigate: (1) how organizations should make strategic decisions in general ${ }^{8,9}$; (2) which factors are known to influence an organization's strategic decision making process ${ }^{10,11}$; (3) the detail and development of e-commerce models ${ }^{12,}{ }^{13}$; and (4) the classification system for the types of e-commerce models ${ }^{12,14}$. However, nowhere have the two disciplines (i.e. strategic decision-making and e-commerce model) been combined, despite their significance in technological innovation ${ }^{15}$, sustaining global competitiveness ${ }^{16}$ and the increasing need to re-think about the existing business models ${ }^{17}$. Furthermore, although e-commerce has emerged since the late 1990s, there still appears a lack of empirical research in the area of how organizations make their strategic decision of B2B e-commerce models to be adopted, which is the key focus of this study.

With limited prior studies conducted, this study posits that the factors impact on the steps and methods used in strategic decision-making are also likely to influence the selection of B2B e-commerce models. Therefore, the key focus of this study is to investigate the impact of these factors on how they will influence an organization's selection of e-commerce models. Hence, 
this paper addresses the question: 'What are the factors influencing the selection of B2B e-commerce models in agribusiness organizations? Why?'.

\section{LITERATURE}

Strategic decision making is a critical process in any organization, which can be regarded as a series of different steps that organizations undertake to formulate strategic decisions ${ }^{18,19}$. Various methods are used to conduct the steps involved in the strategic decision making process ${ }^{20,21}$. In addition, factors both internal and external to the organization will impact the steps and methods used in strategic decision making ${ }^{22,23}$. These factors will be the focus of this study whilst there is little known about how they will influence an organization's selection of models and in particular for this study, e-commerce models. These factors will now be examined in more detail.

There are many factors not only regarded as important influencers on the strategic decision making process, but they may also affect the choice of B2B e-commerce models which itself can be regarded as a strategic decision. This is because the choice of e-commerce models to be adopted will form the framework for organizations to pursue their business activities in the e-commerce environment and more importantly it can also affect organizations' overall strategy and strategic direction ${ }^{24,25}$. These influencing factors can be classified into two categories; internal and external. The literature on organizational strategic decision making suggests that factors that are considered to be within the organization's control are termed internal factors and those beyond the control of the organization are termed external factors ${ }^{26,27}$.

There are nine internal influencing factors identified from the literature. These are: (1) organizational structure and culture ${ }^{19,26} ;(2)$ types of business strategy $^{26,28}$; (3) resources available ${ }^{29,30}$; (4) technological infrastructure and knowledge ${ }^{31,32}$; (5) market positioning ${ }^{30,33}$; (6) on- and off-line marketing strategy and objectives ${ }^{34,35}$; (7) understanding of e-commerce models $^{36,37}$; (8) nature of products or services ${ }^{26,33}$; and (9) target market segment and market scope ${ }^{35,38}$. On the other hand, there are seven external influencing factors identified from the literature that may impact strategic decision making. These are: (1) type of industry or sector ${ }^{26,33}$; (2) buyers and suppliers ${ }^{26,39} ;$ (3) competitors ${ }^{31,32}$; (4) environmental factors ${ }^{10,22} ;$ (5) market trends ${ }^{40,41}$; (6) consultants ${ }^{42,43}$; and (7) strategic partners ${ }^{26,44}$.

Based on the literature reviewed, a preliminary model (Figure 1) was developed suggesting that although the selection of e-commerce models is a unique strategic decision, traditional factors (both internal and external) that 
would normally impact such a decision will apply in this context. Furthermore, the relative importance of each of these factors in the strategic decision process will also be examined as it is proposed that some of these factors may be more important than others.

Internal influencing factors

- Organizational structure and culture

- Types of business strategy

- Resources available

- Technological infrastructure and knowledge

- Market positioning

- On- and off-line marketing strategy and objectives

- Understanding of e-commerce models

- Nature of products or services

- Target market segment and market scope the selection of $B 2 B$

External influencing factors

- Type of industry

- Buyers and suppliers

- Competitors

- Environmental factors

- Market trends

- Consultants

- Strategic partners

Figure 1. Preliminary model for the selection of B2B e-commerce models

\section{METHODOLOGY}

This research was exploratory in nature and had adopted the case study methodology, which was used to confirm or disconfirm the factors influencing the selection of e-commerce models identified in the literature reviewed $^{45}$. The case study approach has been justified on three bases. Firstly, case study research focuses on an organization or industry with the intention to rigorously explore and extensively analyze the contemporary real-life experiences and events while maintaining the holistic and meaningful characteristics of these experiences and events. This captures the richness and depth of contextual meaning (such as the rationales on the factors influencing the selection of e-commerce models) that can give rise to possible new insight ${ }^{45}$. Secondly, the approach undertaken by this research aims to investigate the complexity and dynamism of the context within the organizational settings and events such as the influencing factors for 
selecting e-commerce models in the agribusiness industry ${ }^{45,46}$. Thirdly, case study research provides a more informed basis for theory building than surveys and is considered to be suitable for new research areas or research areas where existing theory seems inadequate ${ }^{45,47}$. As evident in this research, there is a limited number of prior research studies conducted in this area, particularly in the agribusiness industry context. Through case studies, this research will attempt to investigate the complex business environment in the agribusiness industry, which provides a real-life account of the research issues raised in this research and builds on theory for further conclusive research.

Twelve agribusiness cases were judgmentally selected based on the criteria that they have operated in the industry for a minimum of five years and have been involved in B2B e-commerce for at least two years. These 12 cases were equally represented by six large enterprises and SMEs respectively. For each case, two interviews were conducted with the managing director or equivalent (who is involved in managerial activities) and a middle-level manager or operational staff (who is involved in the daily operational activities), to determine if significant differences existed between (1) large enterprise versus SME perspectives and (2) management versus operations viewpoints.

In this research, replication logic in multiple case studies was used to achieve external validity. The construct validity of this study was achieved by the use of multiple sources of evidence through secondary sources (such as the company's business plans, IT plans and other relevant documentations) which were used to further triangulate the results. These interviews were semi-structured in nature and conducted in a flexible and informal manner, which provided a greater sensitivity to potential misunderstandings by interviewees and also revealed greater depth of understanding and information about feelings and emotions toward the specific factors that were considered to be influential to the selection of e-commerce models. Furthermore, a case study protocol was developed and used throughout the interviewing process, in order to enhance the reliability of the study and also to ensure all relevant issues were consistently addressed and conveyed to the interviewees. The duration for each of the in-depth interviews was approximately 60 minutes.

\subsection{Data Analysis}

This research has followed the content analysis procedures that began with the coding of themes in the interview questions, which facilitated in organizing the data for easier retrieval ${ }^{48,49}$. In this analysis, data in each interview was coded in terms of the actual questions on the interview 
protocol, which could assist in revealing relationships and new ideas or areas for coding ${ }^{48,49}$. The coded interviewing questions within each interview were then compared and contrasted to identify the key issues and derive some form of generalization ${ }^{48,49}$. In addition, narrative text and quotations from case studies were used to improve the credibility of data analysis and also to add qualitative insights to the research issues ${ }^{45}$. The findings of this research will be discussed in the next section.

\section{RESEARCH FINDINGS}

There were 24 in-depth interviews conducted with 12 agribusiness cases. The majority of the interviewees (18 out of 24) were male and the remaining six were female. Twenty of the 24 interviewees had more than five years of experience in the agribusiness industry, while the others had at least two years of relevant experience. All interviewees had direct involvement in activities related to conducting B2B e-commerce. A summary of the interviewees' profiles is presented in Table 1.

Table 1. Profiles of the interviewees

\begin{tabular}{ccll}
\hline Case & $\begin{array}{c}\text { Organizational } \\
\text { size }\end{array}$ & \multicolumn{1}{c}{ 1st interviewee position } & 2nd interviewee position \\
\hline A & Large enterprise & Managing director * & IT manager * \\
B & Large enterprise & Executive director * & Business manager \# \\
C & Large enterprise & Director strategic planning \# & Project manager * \\
D & Large enterprise & General manager * & Project manager \# \\
E & Large enterprise & Regional manager * & Technical support manager * \\
F & Large enterprise & Business development & E-commerce specialist * \\
& & manager * & Operations manager * \\
G & SME & Director * & IT manager * \\
H & SME & Owner * & Planning supervisor * \\
I & SME & Owner * & Marketing officer * \\
J & SME & Managing director \# & Project support officer \# \\
K & SME & Business manager * & Planning officer \# \\
L & SME & Director * & S
\end{tabular}

Note: An $(*)$ refers to a male interviewee while a (\#) refers to a female interviewee.

The findings supported 13 factors developed in the preliminary model (Figure 1) as being important to the selection of e-commerce models, while the remaining three other factors (i.e. on- and off-line marketing strategy and objectives, market positioning, and environmental factors) were regarded as being less important. The results also revealed insights into one new factor (i.e., government agencies) that could have a significant impact on the 
selection of e-commerce models. A summary of the results from the case studies is presented in Table 2.

Table 2. Summary results from the case studies

\begin{tabular}{lc}
\hline \multicolumn{1}{c}{ Influencing factors } & $\begin{array}{c}\text { Total number of interviewees } \\
\text { mentioned the factor (out of 24) }\end{array}$ \\
\hline Internal & 23 \\
Resources available & 21 \\
Target market segment and market scope & 19 \\
Nature of products or services & 19 \\
Technological infrastructure and knowledge & 17 \\
Types of business strategy & 16 \\
Organizational structure and culture & 14 \\
Understanding of e-commerce models & 10 \\
On and off-line marketing strategy and objectives* & 10 \\
Market positioning* & \\
\hline External & 18 \\
Strategic partners & 18 \\
Competitors & 15 \\
Type of industry & 15 \\
Consultants & 13 \\
Buyers and suppliers & 13 \\
Government agencies\# & 12 \\
Market trends & 2 \\
Environmental factors* & \\
\hline Nit A tar & \\
\hline
\end{tabular}

Note: A factor was considered important when it was mentioned by at least half of the total number of interviewees. Factors with an $\left(^{*}\right)$ were regarded as less important to the selection of B2B e-commerce models, while a (\#) represents a newly identified factor that was considered to be important.

\subsection{Internal Factors}

The findings revealed that there were seven internal factors regarded to be important to the selection of B2B e-commerce models. All interviewees (23 out of 24) except one agreed that resources available were critical to the selection of e-commerce models. Interviewees agreed that resources (such as human, financial and physical) available were essential in determining the capability of the organization to develop, support and maintain the selected e-commerce model in a feasible manner. Furthermore, effective allocation of available resources could also contribute to improving an organization's total quality management, and therefore it was important to ensure the resources were well matched with the selected e-commerce model. This was supported by an interviewee stating that "We've to ensure that the company has the 
required resources to develop and support a particular e-commerce model so as to compete successfully in the e-commerce environment". Another interviewee also commented that "Regardless of which model we intend to adopt, we have to make sure that the company has the necessary resources to pursue it".

Target market and market scope was another important influencing factor for the selection of e-commerce models, with 21 of the 24 interviewees indicating its importance. Most interviewees suggested that their organizations had to determine the appropriateness of a particular e-commerce model to the nature of their targeted market segments and market scope, as each type of e-commerce model could have different strengths and weaknesses in these areas. Interviewees also agreed that their selected e-commerce models were based on their customers' needs and wants in the various market segments. This is supported by an interviewee commenting that "We have been successful in using this model (solution provider) for a particular market that requires value-added service". Furthermore, the adopted e-commerce model should meet the nature of their target market so that organizations can take advantage of the strengths and benefits characterized by the selected model. Supporting this, an interviewee stated "As we service a wide range of markets (for example Australia, the United States and China), their (target markets) needs would be different".

The nature of products or services was seen to be another important factor that could influence the selection of e-commerce models. Nineteen interviewees suggested that because the functions and characteristics of the types of e-commerce models differ from one another, it was essential for their organizations to determine the appropriateness of the adopted e-commerce model as to whether it would meet the specific nature of the products or services being offered. An interviewee supported this by commenting that "We also offer online services (such as commodity pricing, market analysis, publications) that are different in nature from the commodity like products. It's difficult to fit a single e-commerce model into products and services that are different in nature".

Technological infrastructure and knowledge was nominated by 19 interviewees as being important to their selection of e-commerce models. Interviewees agreed that their organizations' technological infrastructures (for example software programs and networking capabilities) and knowledge (for example e-commerce and computing) were crucial to their selection of e-commerce models. This factor helped organizations determine their technological capability, to develop and support the selected e-commerce model. This was supported by comments from interviewees such as "Having the necessary e-commerce and computer knowledge has provided me a better 
understanding of which e-commerce model is appropriate for our company". "I think it's important to make sure that our company has the necessary technological infrastructure and knowledge to support the model that we intend to adopt".

Seventeen interviewees mentioned that the types of business strategy adopted by their organizations were essential to their selection of e-commerce models. Interviewees believed that the e-commerce model adopted had to fit well into the appropriate business strategy, which would in turn assist their organizations in accomplishing and achieving their overall strategic goals. Some of the supporting comments include, "It's important that we take into consideration our business strategy when selecting the model. We've to make sure that the model selected has to be in line with it (business strategy)". "I'm always being reminded that the model adopted has to be able to support and achieve the objectives of the business strategy".

Another important factor influencing the selection of e-commerce models was organizational structure and culture, which was supported by 16 interviewees. Interviewees indicated that organizational structure and culture were not only seen to dictate how objectives and policies were to be established within an organization, but they also have an impact on strategic decision-making, which included the selection on e-commerce models. An interviewee supported this by commenting that "It's important that any strategic decisions made, including one like this (selection of e-commerce models) are focused on achieving the goals and objectives of the company". Furthermore, interviewees also believed that e-commerce models that conflict with an organization's culture would be difficult to implement, as the model would not generally be supported within the organization. This was supported by an interviewee's comment that "I've been with the company for many years and I believe that the company's culture has greatly affected the way we make decisions and do things. This also includes how and why we've selected particular models to conduct our business".

Fourteen of the 24 interviewees agreed that it was important for them to acquire an understanding of the various types of e-commerce models (including their respective functions and characteristics) to assist them in their e-commerce model selection. This is because different e-commerce models might be more suitable and applicable for different situations, industries, or markets. Thus, having a good understanding of the e-commerce models would influence their choice of the model being adopted. This was supported by interviewees who commented "When I was selecting an e-commerce model, I tried to understand the models and how are they different from one another". "It'll be very difficult for me to select a 
particular e-commerce model if I don't have any understanding of these models".

\subsection{External Factors}

The findings revealed that there were six external factors identified as important to the selection of e-commerce models. The influence of strategic partners was regarded as an important factor by 18 interviewees. Interviewees acknowledged that strategic partners were crucial to their selection of e-commerce models as these partnerships were formed to achieve mutual goals and interest. Therefore, organizations had to consider their strategic partners' opinions and viewpoints prior to making any strategic decisions, which included their choice of e-commerce models. This was supported by an interviewee who stated "We've formed several strategic partnerships to enhance our position in the industry and it's difficult to ignore their opinions and decisions since we've a commitment to each other". Furthermore, the selection of a particular e-commerce model that was resisted by the strategic partners could potentially jeopardize the long-term business relationships. An interviewee supported this by commenting that "I believe that our choice of models will be affected by our strategic partners. We can't possibly use a model that contradicts our agreed interest".

Eighteen interviewees acknowledged that competitors were an important influencing factor to their selection of e-commerce models. Interviewees suggested that organizations tended to monitor their respective competitors' strategic changes and any developments that might affect or threaten their competitiveness. In order to maintain a competitive position within the relevant industry, organizations would respond to the decisions or actions of their competitors, and develop and implement appropriate strategies that were influenced by said decisions or actions, including the choice of e-commerce models to be selected. Furthermore, interviewees also believed that it was worthwhile for organizations to learn what their competitors had done in relation to the selection of e-commerce models. This would enable the organizations to gain second-mover advantages (such as shorter learning curve periods) that allow them to compete more effectively in the industry. In supporting this, some interviewees commented that "I've spent some time observing our major competitors on what and why they have selected a particular model". "We do look around and see what others (competitors) have done or are doing, so that we can make a better choice on our selected model".

Fifteen interviewees had considered the type of industry as an important influencing factor for the selection of e-commerce models. It was suggested that certain e-commerce models might be more suitable for specific industries 
where their respective features and characteristics would match with the e-commerce models available. In addition, interviewees also agreed that the nature of the agribusiness industry is commodity-like and is generally regarded as a slower adopter of technology and e-commerce activities when compared to other industries (such as the telecommunication industry). Therefore, e-commerce models adopted by agribusiness organizations might differ from those considered by organizations in other industries. This was supported by comments from interviewees stating "The nature of the agribusiness industry is commodity-like while other industries might be different". "If we were in a different industry, I think our company may be adopting different models. We have to match the model to the nature of the industry".

Fifteen interviewees nominated the influence of consultants as a critical factor to their selection of e-commerce models. Interviewees indicated that they tended to seek advice from consultants (formally or informally) when making strategic decisions that might affect the organization as a whole. These consultants could be established either as a strategic group within the organization (usually in large enterprises), or outsourced externally. Interviewees acknowledged that consultants had the required expertise and knowledge to guide them into selecting the e-commerce models that best suited their organizations' needs. This was supported by comments from interviewees such as "Advice from consultants is very important to us, particularly when making important business decisions. We have sought their opinions on what models to be adopted and how we should be doing it". "External consultants have provided us with some good advice on our choice of e-commerce models to be adopted".

There were 13 interviewees who suggested that buyers' and suppliers' influence were not only critical to their selection of e-commerce models but could also affect the strategic decisions of one another. Interviewees believed that buyers and suppliers were the basic elements in forming business relationships and that these relationships existed in any business environment where the actions and decisions of each could impact one another; thus, they would expect their selection of e-commerce models to be affected by this factor. The importance of this factor was particularly evident in organizations that had established strong and long-term business relationships with their counter parts (i.e., buyers and suppliers). This was supported by comments from interviewees stating that "I believe this factor is important to the choice of e-commerce models because there's a close relationship between companies and farmers in this industry". "To a certain extent, I'm sure they'll have some influences to my decision on which model to select". 
The final factor considered to be important to the selection of e-commerce models was market trends, which was nominated by 12 interviewees. Interviewees suggested that this factor played an essential role when organizations were pursuing a "trendy" corporate image, where they would not want to be perceived as "out of touch" or market losers. Furthermore, it was believed that organizations should be at the vanguard of market trends, where they could be regarded as the market leader in the promotion of e-commerce adoption in the agribusiness industry. This was supported by interviewees who commented that "I believed that our company's intention of adopting those models is to show the market that we're among the best that are conducting e-commerce activities in this industry (agribusiness)". "When our company decides to get involved in e-commerce, I was told by the management to find out what's the market trend (in terms of the most commonly used model)".

\subsection{Differences within Agribusinesses}

There were differences in the responses to four factors based on organizational size and between management and operational perspectives. Interviewees from large enterprises had considered the type of industry to be a critical factor influencing their selection of e-commerce models. This was because they believed that there existed some key differences in characteristics between industries and that there was no one e-commerce model that would match these differing characteristics. Thus, a model might be selected in accordance with the industry that the organization was operating in. This was supported by an interviewee commenting that "I've been in two different industries (agribusiness and computing). I can say that the models that we're using now may not be suitable to the computing industry because they're different in nature and environment". In contrast, interviewees from SMEs argued that this factor was not important to their selection of e-commerce models because they perceived e-commerce to be boundless and that the industry that the organization was operating in had little influence on the choice of models. Some supporting comments from the interviewees included "I don't think the type of industry we're in will make any difference to the model that we select". "Nothing can be changed to the type of industry we're currently in".

On the other hand, interviewees from SMEs were more concerned with two other factors: buyers and suppliers, and government agencies. Interviewees stressed the importance of the close working relationships they have with their buyers and suppliers, and this was particularly evident for those relationships that had been well established over a period of time. Thus, they believed that this factor could have an impact on the selection of e-commerce models. This was supported by interviewees' comments stating 
that "My choice of models could be affected by them (buyers or suppliers) if we have developed and maintained a good relationship for a long period of time". "We have to setup some kind of computer network with one major buyer so that they're willing to conduct business with us. I think when we're selecting a model, their influences cannot be ignored". However, interviewees from large enterprises argued that due to their organizations being larger in size, they actually had the power to influence their buyers and suppliers in various different areas, including the choice of e-commerce models to be adopted. An interviewee supported this by commenting that " $I$ don't think we're affected by them (buyers and suppliers). In fact, I think we're the one that actually influenced some of their decisions on the models that they have selected".

Interviewees from SMEs also considered the influence of government agencies as important to the selection of e-commerce models. This was supported by an increasing number of SMEs seeking assistance from government agencies for advices on the conduct of e-commerce activities, including the selection of e-commerce models. Furthermore, the agribusiness industry was also in its early stage of e-commerce adoption and thus relying on the government to provide necessary support and assistance to make a smooth transition to the e-commerce environment. This was supported by an interviewee commenting that "We rely on them (government agencies) to give us advice on what or how the process in adopting not just models but e-commerce as a whole". However, interviewees from large enterprises believed that they had adequate knowledge and experiences (due to their global exposure) in selecting e-commerce models and did not necessarily require much advice from government agencies. An interviewee supported this with the comment "We are a company with many years of international experience and this has helped us in making sound strategic decisions. And the selection of e-commerce models is not something new to us. We would rather rely on our successful experience than on some government advice that has yet to be tested".

From the management's perspective, interviewees had regarded consultants as an important influencing factor to their selection of e-commerce models. Interviewees agreed that consultants' opinions were often sought on matters related to strategic decision-making, and they could also provide recommendations that were most appropriate to their organizations' needs. This was supported by an interviewee's comment "I will ask for consultant's advice whenever strategic decisions are required and this includes selecting a model'. In contrast, interviewees from the operational perspective argued that consultants had little influence on their selection of e-commerce models. This was mainly due to the fact that 
operational personnel had minimal contact with consultants and very few opportunities to be involved in any discussions with consultants. Some of the supporting comments from interviewees include "I don't usually get in touch with consultants, therefore I don't think they'll influence my decision on which model to be adopted". "The consultants only do presentations to the directors, I have no contact with them. I don't think I'll be affected by them when selecting the model". "This factor (consultants' influence) is unlikely to affect my decision on the models to be adopted since I've very limited contact with them (consultants)".

\section{CONCLUSIONS, CONTRIBUTIONS AND IMPLICATIONS}

This study has investigated the factors influencing the selection of B2B e-commerce models in the Australian agribusiness industry. On the whole, findings revealed the support for 13 of the 16 factors identified in the preliminary model as important to the selection of B2B e-commerce models. There were seven internal factors: (1) resources available; (2) target market segment and market scope; (3) nature of products or services; (4) technological infrastructure and knowledge; (5) types of business strategy; (6) organizational structure and culture; and (7) understanding of e-commerce models, regarded as important to the selection of e-commerce models. In addition, agribusinesses had also considered six external factors to be influential to their e-commerce models selection, namely: (1) strategic partners; (2) competitors; (3) type of industry; (4) consultants; (5) buyers and suppliers; and (6) market trends. The findings also identified one additional factor (i.e., government agencies) as influential to the selection of B2B e-commerce models, which was not included in the preliminary model (Figure 1). In contrast, there were three factors (i.e. on- and off-line marketing strategy and objectives, market positioning, and environmental factors) identified as less important to the selection of e-commerce models.

Analysis of the interview data also highlighted some variations in attitudes towards the importance of four factors (i.e. type of industry, buyers and suppliers, government agencies, and consultants) based on organizational size (i.e., large enterprises versus SMEs) and between management and operational perspectives. Furthermore, it should also be noted that the selection of B2B e-commerce models was often influenced by a combination of factors and not just by a single dominant factor. 


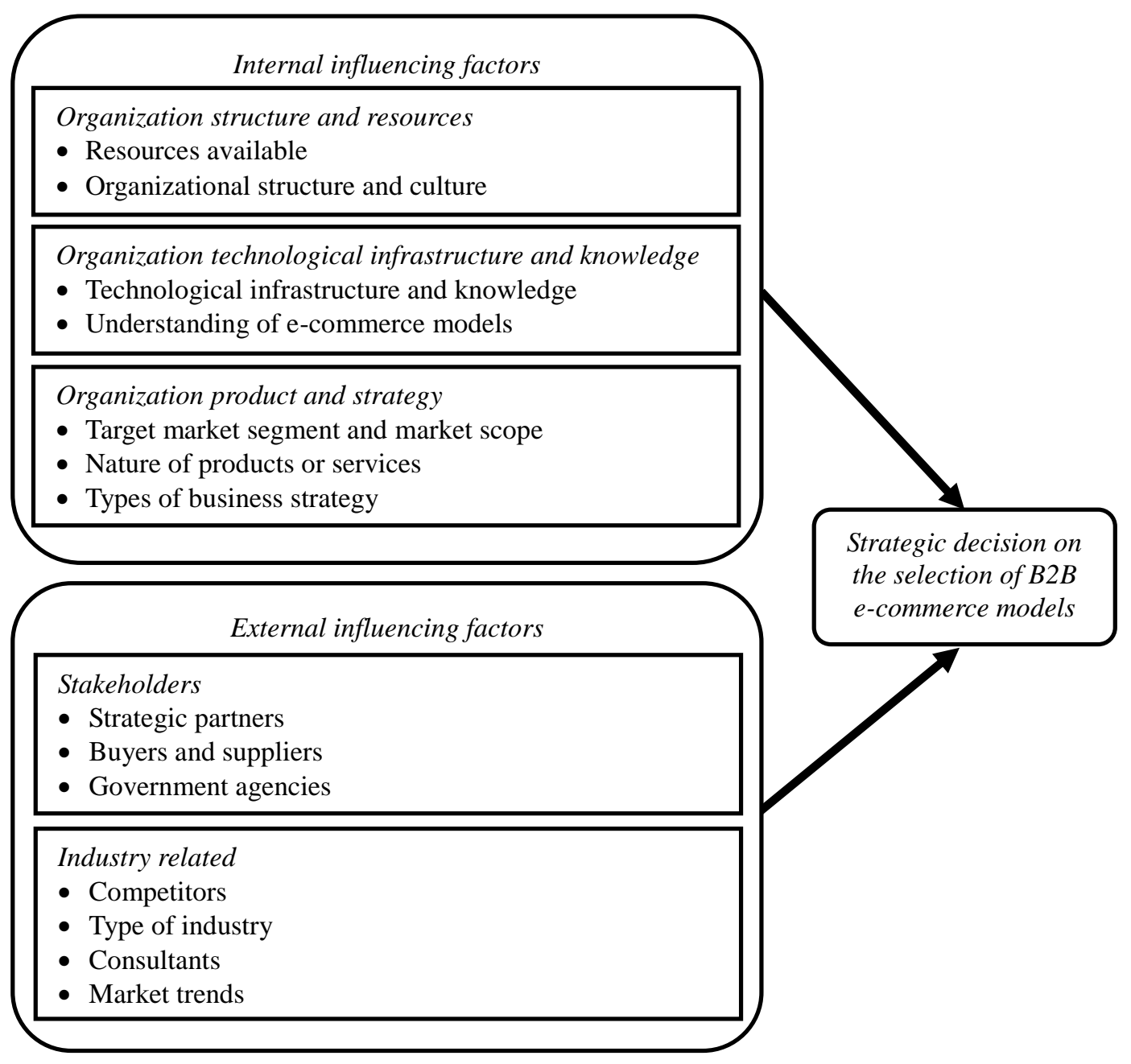

Figure 2. Revised theoretical model for the selection of B2B e-commerce models

The key contribution of this research is the development of a theoretical model for the selection of e-commerce models in a B2B electronic environment that includes the identification of important factors influencing the selection of e-commerce models for agribusiness, which had been identified as an area that lacked empirical research. In addition, this research has also brought together two disciplines (i.e., strategic decision-making and e-commerce models) that had not previously been adequately studied collectively. The findings from this research have also added new insights to the existing literature with the identification of the factor of government agencies as important to the selection of e-commerce models. This provides a more comprehensive revised theoretical model 
(Figure 2) to be considered by agribusinesses. In addition, this research also contributes to the practice and managerial strategic decision-making where the findings were based on practitioners' experiences and opinions, which provided a greater relevance in managerial planning and decision-making processes.

\section{LIMITATIONS AND RECOMMENDATIONS FOR FUTURE RESEARCH}

This research investigated the initial development of a theoretical model for the selection of B2B e-commerce models within the context of the Australian agribusiness industry and therefore cannot be generalized to other markets and industries, or the population at large. A more representative sampling population should be sought and tested in order to generalize the findings. Future research could focus on confirming the developed theoretical model and replicating this research in other contexts.

\section{REFERENCES}

[1] T.E. Porterfield, J.P. Bailey, and P.T. Evers, B2B eCommerce: An empirical investigation of information exchange and firm performance. International Journal of Physical Distribution \& Logistics Management, 40(6), p435-455, 2010. http://dx.doi.org/10.1108/09600031011062182.

[2] S. Ryu, and K. Hung, E-commerce transaction mechanisms and buyer-supplier relationship. Journal of Business \& Economic Research, 7(2), p79-92, 2009.

[3] S. Drew, Strategic uses of e-commerce by SMEs in the east of England. European Management Journal, 21(1), p79-88, 2003. http://dx.doi.org/10.1016/S0263-2373(02)00148-2.

[4] B.W. Wirtz, O. Schilke, and S. Ullrich, Strategic development of business models: Implications of the web 2.0 for creating value on the internet. Long Range Planning, 43(2-3), p272-290, 2010. http://dx.doi.org/10.1016/j.lrp.2010.01.005.

[5] E. Elia, L-A. Lefebvre, and E. Lefebvre, Focus of B-to-B e-commerce initiatives and related benefits in manufacturing small- and medium-sized enterprises. Information Systems and E-Business Management, 5(1), p1-23, 2007. http://dx.doi.org/10.1007/s10257-006-0035-8.

[6] Y. Nakayama, The impact of e-commerce: It always benefits consumers, but may reduce social welfare. Japan and the World 
Economy, 21(3), p239-247, 2009. http://dx.doi.org/10.1016/j.japwor.2008.10.001.

[7] K. Reimers, M. Li, and G. Chen, A multi-level approach for devising effective B2B e-commerce development strategies with an application to the case of China. Electronic Commerce Research, 4(3), p287-305, 2004. http://dx.doi.org/10.1023/B:ELEC.0000027984.15737.cb.

[8] C.L. Citroen, The role of information in strategic decision-making. International Journal of Information Management, 31(6), p493-501, 2011. http://dx.doi.org/10.1016/j.ijinfomgt.2011.02.005.

[9] L. Liberman-Yaconi, T. Hooper, and K. Hutchings, Towards a model of understanding strategic decision-making in micro-firms: Exploring the Australian information technology sector. Journal of Small Business Management, $\quad 48(1), \quad$ p70-95, 2010. http://dx.doi.org/10.1111/j.1540-627X.2009.00287.x.

[10] S. Elbanna, and J. Child, Influences on strategic decision effectiveness: Development and test of an integrative model. Strategic Management Journal, 28(4), p431-453, 2007. http://dx.doi.org/10.1002/smj.597.

[11] W. Ho, X. Xu, and P.K. Dey, Multi-criteria decision making approaches for supplier evaluation and selection: A literature review. European Journal of Operational Research, 202(1), p16-24, 2010. http://dx.doi.org/10.1016/j.ejor.2009.05.009.

[12] M. Rappa, Business models on the web. Retrieved on May 5, 2013, from http://digitalenterprise.org/models/models.html.

[13] P.M.C. Swatman, C. Krueger, and K. Van Der Beek, The changing digital content landscape: An evaluation of e-business model development in European online news and music. Internet Research, 16(1), p53-80, 2006. http://dx.doi.org/10.1108/10662240610642541.

[14] M. Dubosson-Torbay, A. Osterwalder, and Y. Pigneur, E-business model design, classification, and measurements. Thunderbird International Business Review, 44(1), p5-23, 2002. http://dx.doi.org/10.1002/tie.1036.

[15] K. Zhu, K.L. Kraemer, and S. Xu, The process of innovation assimilation by firms in different countries: A technology diffusion perspective on e-business. Management Science, 52(10), p1557-1576, 2006. http://dx.doi.org/10.1287/mnsc.1050.0487.

[16] R.G. Javalgi, L.P. Radulovich, G. Pendleton, and R.F. Scherer, Sustainable competitive advantage of internet firms: A strategic framework and implications for global marketers. International Marketing Review, 22(6), p658-672, 2005. http://dx.doi.org/10.1108/02651330510630276.

[17] D.J. Teece, Business models, business strategy and innovation. Long Range Planning, 43(2/3), p172-194, 2010. http://dx.doi.org/10.1016/j.lrp.2009.07.003. 
[18] G. Jocumsen, How do small business managers make strategic marketing decisions?: A model of process. European Journal of Marketing, 28(5/6), p659-674, 2004. http://dx.doi.org/10.1108/03090560410529277.

[19] G. Johnson, R. Whittington, and K. Scholes, Exploring strategy $\left(9^{\text {th }}\right.$ ed.). Harlow: Financial Times Prentice Hall, 2011.

[20] W. Kwon, I. Clarke, and R. Wodak, Organizational decision-making, discourse, and power: integrating across contexts and scales. Disclosure \& Communication, 3(3), p273-302, 2009. http://dx.doi.org/10.1177/1750481309337208.

[21] B.J. Olson, S. Parayitam, and Y. Bao, Strategic decision making: The effects of cognitive diversity, conflict, and trust on decision outcomes. Journal of Management, 33(2), p196-222, 2007. http://dx.doi.org/10.1177/0149206306298657.

[22] S. Elbanna, and J. Child, The influence of decision, environmental and firm characteristics on the rationality of strategic decision-making. Journal of Management Studies, 44(4), p561-591, 2007. http://dx.doi.org/10.1111/j.1467-6486.2006.00670.x.

[23] H. Hansson, and R. Ferguson, Factors influencing the strategic decision to further develop dairy production: A study of farmers in central Sweden. Livestock Science, 135(2/3), p110-123, 2011. http://dx.doi.org/10.1016/j.livsci.2010.06.157.

[24] F. Hacklin, and M. Wallnöfer, The business model in the practice of strategic decision making: Insights from a case study. Management Decision, 50(2), p166-188, 2012. http://dx.doi.org/10.1108/00251741211203515.

[25] P.A. Phillips, and C. Wright, E-business's impact on organizational flexibility. Journal of Business Research, 62(11), p1071-1080, 2009. http://dx.doi.org/10.1016/j.jbusres.2008.09.014.

[26] F.R. David, Strategic management: Concepts and cases $\left(12^{\text {th }}\right.$ ed.). Upper Saddle River, NJ: Pearson Education, 2009.

[27] H. Walker, L. Di Sisto, and D. McBain, Drivers and barriers to environmental supply chain management practices: Lessons from the public and private sectors. Journal of Purchasing and Supply Management, 14(1), p69-85, 2008. http://dx.doi.org/10.1016/j.pursup.2008.01.007.

[28] C. Zott, and R. Amit, The fit between product market strategy and business model: Implications for firm performance. Strategic Management Journal, 29(1), p1-26, 2008. http://dx.doi.org/10.1002/smj.642.

[29] C.M. Lau, Team and organizational resources, strategic orientations, and firm performance in a transitional economy. Journal of Business 
Research, 64(12), p1344-1351, 2011. http://dx.doi.org/10.1016/j.jbusres.2011.01.001.

[30] A. Lockett, S. Thompson, and U. Morgenstern, The development of the resource-based view of the firm: A critical appraisal. International Journal of Management Reviews, 11(1), p9-28, 2009. http://dx.doi.org/10.1111/j.1468-2370.2008.00252.x.

[31] K.D. Brouthers, L.E. Brouthers, and S. Werner, Real options, international entry mode choice and performance. Journal of Management Studies, 45(5), p936-960, 2008. http://dx.doi.org/10.1111/j.1467-6486.2007.00753.x.

[32] K.Z. Zhou, J.R. Brown, C. Dev, and S. Agarwal, The effects of customer and competitor orientations on performance in global markets: A contingency analysis. Journal of International Business Studies, $\quad 38(2), \quad$ p303-319, 2007. http://dx.doi.org/10.1057/palgrave.jibs.8400259.

[33] P. Timmers, Electronic commerce: strategies and models for business-to-business trading. Singapore: John Wiley \& Sons, Ltd, 1999.

[34] A. Krasnikov, and S. Jayachandran, The relative impact of marketing, research-and-development, and operations capabilities on firm performance. Journal of Marketing, 72(4), p1-11, 2008. http://dx.doi.org/10.1509/jmkg.72.4.1.

[35] R. Varadarajan, Strategic marketing and marketing strategy: Domain, definition, fundamental issues and foundational premises. Journal of the Academy of Marketing Science, 38(2), p119-140, 2010. http://dx.doi.org/10.1007/s11747-009-0176-7.

[36] S.R. Magal, P. Kosalge, and N.M. Levenburg, Using importance performance analysis to understand and guide e-business decision making in SMEs. Journal of Enterprise Information Management, 22(1/2), p137-151, 2009. http://dx.doi.org/10.1108/17410390910932795.

[37] R. Samavi, E. Yu, and T. Topaloglou, Strategic reasoning about business models: A conceptual modeling approach. Information Systems and E-Business Management, 7(2), p171-198, 2008. http://dx.doi.org/10.1007/s10257-008-0079-z.

[38] D.A. Griffith, Understanding multi-level institutional convergence effects on international market segments and global marketing strategy. Journal of World Business, 45(1), p59-67, 2010. http://dx.doi.org/10.1016/j.jwb.2009.04.006.

[39] R. Dekkers, Impact of strategic decision making for outsourcing on managing manufacturing, International Journal of Operations \& Production Management, 31(9), p935-965, 2011. http://dx.doi.org/10.1108/01443571111165839. 
[40] M. Borges, N. Hoppen, and F. Bins Luce, Information technology impact on market orientation in e-business. Journal of Business Research, 62(9), p883-890, 2009. http://dx.doi.org/10.1016/j.jbusres.2008.10.010.

[41] A.Y-H. Chong, K-B. Ooi, B. Lin, and S.Y. Tang, Influence of interorganizational relationships on SMEs' e-business adoption. Internet Research, 19(3), p313-331, 2009. http://dx.doi.org/10.1108/10662240910965379.

[42] L. Crawford, and A.H. Nahmias, Competencies for managing change. International Journal of Project Management, 28(4), p405-412, 2010. http://dx.doi.org/10.1016/j.ijproman.2010.01.015.

[43] K.T. Haynes, and A. Hillman, The effect of board capital and CEO power on strategic change. Strategic Management Journal, 31(11), p1145-1163, 2010. http://dx.doi.org/10.1002/smj.859.

[44] M. Sambasivan, L. Siew-Phaik, Z.A. Mohamed, and Y.C. Leong, Impact of interdependence between supply chain partners on strategic alliance outcomes: Role of relational capital as a mediating construct. Management Decision, 49(4), p548-569, 2011. http://dx.doi.org/10.1108/00251741111126486.

[45] R.K. Yin, Case study research: Design and methods ( $4^{\text {th }} e d$.). Thousand Oaks, California: Sage Publications, 2009.

[46] D. Carson, A. Gilmore, C. Perry, and K. Gronhaug, Qualitative marketing research. London, Great Britain: Sage Publications, 2002.

[47] K. Eisenhardt, Building theory from case study research. Academy of Management Review, 14(4), p532-550, 1989. http://dx.doi.org/10.2307/258557.

[48] B.L. Berg, Qualitative research methods for the social sciences $\left(4^{\text {th }}\right.$ ed.). Boston: Allyn and Bacon, 2001.

[49] W.L. Neuman, Basics of Social Research: Quantitative and Qualitative Approaches (2 $2^{\text {nd }}$ ed.). Boston: Allyn and Bacon, 2007. 